\title{
The Research Status of Surface Tolerant Anticorrosion Coatings in China
}

\author{
Hong-Yao SUN ${ }^{1,2, a,{ }^{*}}$ Gao-Xia SUN ${ }^{1,2, b}$ Xue-Chuan WANG ${ }^{1,2,3, c}$ \\ ${ }^{1}$ Nanjing Hydraulic Research Institute, China; \\ ${ }^{2}$ State Key Laboratory of Hydrology-Water Resources and Hydraulic Engineering, China; \\ ${ }^{3}$ College of Mechanics and Material, Hehai University, China \\ a,*rehaha@163.com, ${ }^{b}$ gxsun@nhri.cn, ${ }^{\mathrm{c}} 835830127 @ q q . c o m$ \\ * Corresponding author
}

Key words: Surface tolerant coating, Anticorrosion, Present state, Steel, Surface treatment

\begin{abstract}
The surface cleanliness grade of some steel structures which are in the harsh environment such as in tidal and splash zone or are hard to construct on site is difficult to meet the requirements of high grade such as cleanliness grade $\mathrm{Sa}_{2} \frac{1}{2}$ (ISO 8501). There may be water, rust and original coating on the steel surface or the curing reaction may occur in water. So the surface tolerant coatings may be the most suitable method to protect these steel structures. The present research status and development trend of surface tolerant coatings in China including coatings used on rubiginous steel and coatings curing in water are reviewed with the requirements, classification, performance evaluation \& etc.
\end{abstract}

\section{Introduction}

According to statistics, the influence of surface treatment quality on service life of steel constructions is as high as $70 \%$. In order to ensure the anticorrosion quality of the coatings, the surface of the steel must be thoroughly cleaned, and the cleanliness degree is generally required to reach cleanliness grade $\mathrm{Sa}_{2} \frac{1}{2}$ (ISO 8501). Due to the harsh environment, the steel surface cannot meet the requirements of drying, no rust, no original coating, oil free and easy construction, for example, the cleanliness grade $\mathrm{Sa}_{2}{ }^{1}{ }_{2}$ of surface treatment level of the steel structure in ocean tidal and splash zone, inner of oil tank, in rapid repair sluice and in the bridge which construction equipment is hard to reach is difficult to reach (shown in Fig. 1 and Fig. 2). Generally, the surface of this kind of structure can only be handled by hand tools to reach the cleanliness grade St2(ISO 8501), and sometimes the surface also has the water, the original coating, etc..

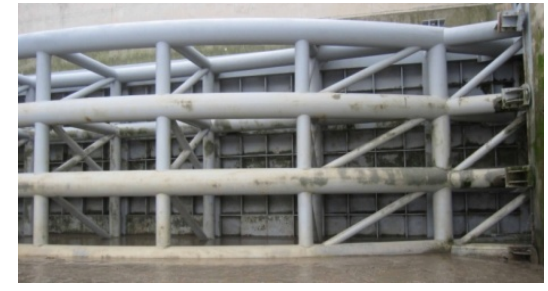

Fig.1 A sluice gate

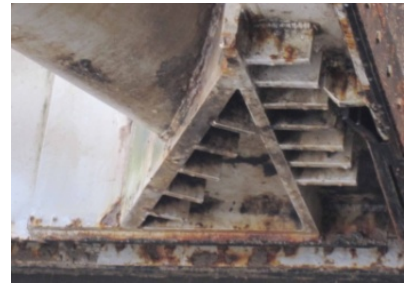

Fig.2 A sluice connection

The problem put forward above can be solved by using surface tolerant coatings. Surface tolerant coatings are required to be coated on the surface with rust, wet or/and original coating etc.

\section{Types of Surface Tolerant Coatings}

According to the steel surface state, surface tolerant coatings can be divided into: coating on rubiginous surface, coating on wet surface, coating on oil surface, coating on original coating surface, coating on composite surface (two or more of the rust, wet, oil and original coating) and 
coating curing in water. According to the resin types forming coating film, surface tolerant coatings can be divided into: epoxy resin coating, polyurethane coating, asphalt modified coating, alkyd resin coating, acrylic resin coating, etc. The most commonly used is epoxy resin surface tolerant coatings with composite functions.

\section{The Characteristics of Surface Tolerant Coating}

Rust-bearing coatings were developed since 1960s and were applied on some engineering. The surface tolerant coatings are developed gradually about after 2000. The characteristics of surface tolerant coatings are shown in Table 1.

Table 1. The characteristics of surface tolerant coatings

\begin{tabular}{|l|l|}
\hline Characteristic & Description \\
\hline Cleanliness grade & The cleanliness grade must be at least ISO 8501 St2 \\
\hline Rubiginous surface & $\begin{array}{l}\text { Flash-rust and rust firmly adhered on the surface may be kept on } \\
\text { the surface, but the quantity of flash-rust must be little. }\end{array}$ \\
\hline Original coating surface & $\begin{array}{l}\text { Original coating must firmly adhere on the surface and must } \\
\text { match with the surface tolerant coating }\end{array}$ \\
\hline Environment conditions & $\begin{array}{l}\text { Relative humidity may be higher than 90\% and the temperature } \\
\text { must be above } 5^{\circ} \mathrm{C} \text { when constructing. }\end{array}$ \\
\hline Wet surface & $\begin{array}{l}\text { The surface tolerant coating can be coated on wet surface if } \\
\text { necessary }\end{array}$ \\
\hline Curing in water & $\begin{array}{l}\text { The surface tolerant coating can cure in water when used in ocean } \\
\text { tidal and splash zone and can construct on-site }\end{array}$ \\
\hline
\end{tabular}

\section{The Research Status of Surface Tolerant Coatings}

Because the coating is hard to adapt to different oil pollution surface, seldom researchers do the research work on coatings used on oil surface. So the future research focus is about the surface tolerant coatings used on rubiginous steel surface, wet surface, and original coating surface and coatings curing in water. The review of rust-bearing coatings was given in the paper[1].

The corrosion degree of the steel structures in ocean tidal zone and the splash zone is more serious than that in air or land, and the corrosion rate in ocean tidal zone and the splash zone is almost 10 times faster than in land[2]. When these structures need maintain or repair, they must be maintained or repaired in-situ and some structures are hard to be moved to land, or the cost of moving to land is too high. The surface tolerant coatings with the property of curing in water or on humid surface may be the best method to protect these steel structures. The coatings curing in water have been researched and developed in the world since 1980s [3]. The preparation of coating curing in water must meet the surface states which there are rust, water, original coating on the surface and the coating must cure quickly to prevent the coating from being washed away by water. So the research status of coatings curing in water can express that of surface tolerant coatings.

\section{The Required Properties of Coatings Curing in Water}

Water on the steel surface is the most unfavorable factor for coating construction and film curing, so the water on the steel surface before coating construction should be managed to be reduced and eliminated. The surface tolerant coatings curing in water should have these characteristics listed in Table 2 [4-6].

\section{The Film-Forming Resins}

The common used anticorrosion coating systems applied under water are [7]: ethylene resin system, polyester resin system, polyurethane system and epoxy resin system etc.. The epoxy resin system is the most suitable system for preparing coatings curing in water. There are a large number of polar groups in the epoxy resin system [4,7] which can replace the water on the substrate surface. The 
ring-opening polymerization of epoxy resin is almost not affected by water and the shrinkage rate of volume after curing is only about $2 \%$.

The adhesive strength and anticorrosion character of epoxy resin coatings are excellent. The solvent-free coatings with super thick film can be prepared easily with epoxy resin. Some epoxy resin surface tolerant coatings produced at home and abroad are listed in Table 3.

Table 2. The required properties of coatings curing in water

\begin{tabular}{|l|l|}
\hline Property & Requirement \\
\hline surface tension & $\begin{array}{l}\text { The surface tension of coatings should be smaller than that of water to } \\
\text { let coatings wet the substrate surface sufficiently. }\end{array}$ \\
\hline Viscosity & In order to paint easily, the coatings should have a suitable viscosity. \\
\hline solubility & The coatings cannot be dissolved in water. \\
\hline $\begin{array}{l}\text { Adhesive strength } \\
\text { on wet surface }\end{array}$ & $\begin{array}{l}\text { The coating must have high adhesive strength on the wet surface and the } \\
\text { water on the substrate surface must be discharged or the little quantity } \\
\text { water on the surface can be absorbed or transformed. }\end{array}$ \\
\hline $\begin{array}{l}\text { Resin and curing } \\
\text { agent }\end{array}$ & $\begin{array}{l}\text { The curing agent and resin should react in water at room temperature or } \\
\text { low temperature and they should not be sensitive to water. }\end{array}$ \\
\hline Reaction speed & $\begin{array}{l}\text { The reaction speed must be rapid to prevent the coating from being } \\
\text { washed out by the water flow and to ensure the coating to firmly attach } \\
\text { to the surface }\end{array}$ \\
\hline Solvent & $\begin{array}{l}\text { Because the curing reaction is done in water, organic solvent is not } \\
\text { suitable The coating curing in water should be solvent free or water-base } \\
\text { coating. }\end{array}$ \\
\hline Characters & $\begin{array}{l}\text { The coatings curing in water should have excellent physical and } \\
\text { mechanical properties and anticorrosion property. }\end{array}$ \\
\hline
\end{tabular}

Table 3. Epoxy resin surface tolerant coatings at home and abroad

\begin{tabular}{|c|c|c|c|c|}
\hline & Company & Product name & Company & Product name \\
\hline \multirow{5}{*}{ Abroad[8] } & PPG & Ameroncoat 400、 Sigmacover 620 & Kansai & Newfort \\
\hline & Euron & Euronavy ES301 & Jotun & Jotun mastic 87 \\
\hline & Akzol Nobel & Interseal 670HS & Rust-Oleum & 9100 \\
\hline & Nippon & Nippon Hl-epoxy 1409 & Carbolin[9] & Carbomastic 15 \\
\hline & Hemple & Hempadur Quattro & & \\
\hline \multirow[b]{2}{*}{ China } & Omelon & Omelon PE35 & Kailing & H53-51,H53-52 \\
\hline & Asdon & $\begin{array}{l}\text { Asdon33305,33306,33307,3305,3 } \\
\text { 306,3310,3311,3312,3322,3336 }\end{array}$ & Hongshi & HSG 0610 \\
\hline
\end{tabular}

The adhesion mechanism of epoxy resin coatings may be [10]: at first, the water molecules adsorbed on the substrate surface shall be replaced by curing agent (such as polyamide resin); and then the water molecules shall move out from the film with the curing reaction proceeding and at the end the coating shall adhere to the substrate firmly in water.

Jian-jun FANG et al.[2] used low viscosity epoxy resin with low epoxy value for preparing solvent-free coating curing in water. The coating can be coated on the wet substrate surface or under water with good construction, thick film, recoatability and excellent anticorrosion property. Cheng-lou LIU et al.[7] prepared a two-component coating curing in water by using liquid epoxy resin DER351 as the basic material, liquid polysulfur rubber JLY-121 as toughening agent, modified fatty amine and modified phenolic amine with cashew as curing agent, aluminum tripolyphosphate as filler. The coating can be coated on the rust-bearing or/and wet surface or under water with rapid reaction speed and high adhesive strength and good anticorrosion property. The heavy-duty anticorrosive epoxy resin coating which can be constructed under water was obtained by Jin-ren WANG et al.[3]. The modified epoxy resin was obtained by reacting epoxy-amine adduct with semiclosure toluene diisocyanate (TDI). Yun-lu CAI et al.[11] developed a solvent-free epoxy resin heavy-duty anticorrosion coating which composed low molecular weight epoxy resin, special fatty acid soap, organic nitrogen base and mineral water-absorption agent etc. 


\section{The Curing Agents}

It is difficult to obtain excellent performance for common used epoxy resin curing agents such as phenolic amine, organic amine and organic acid anhydride when construction and curing reaction are done underwater. The curing agents used in water should be insoluble in water and cannot be emulsified by water; they must have suitable viscosity and polarity; they can wet the surface in water and can react fast and have high adhesive strength.

A coating curing in water which was obtained by using epoxy resin and modified curing agent was developed by Xiao-hong YANG[5]. The ethyl silicate or sulfocarbamide reacts with diethylenetriamine or triethylenetetramine to form the modified curing agent. The coating which was developed by Xiang-ou WU[12] can cure completely after $11-12 \mathrm{~h}$ in water at $25^{\circ} \mathrm{C}$ with epoxy resin and curing agent which was formed by reacting with phenol, formaldehyde, toluene, ethylenediamine and isopropyl glycidyl ether. A curing agent for curing in water in epoxy resin coating system was developed by Zhi-qiang PENG[4]. Ji-su CHEN[13] developed a solvent-free epoxy resin anticorrosion coating by mixing curing agent 1085 and 810 which can cure in water. The coating can be coated and cure in water at 5-12 ${ }^{\circ} \mathrm{C}$. Jin-ren WANG etc.[3] developed a coating curing in water with a solvent-free curing agent by using a composite curing agent which composed a curing agent curing in water and a curing agent formed from the reaction of cashew oleic acid and tung oil fatty acid and an amine. Cheng-lou LIU[7] developed a curing agent curing in water with modified fatty amine and modified phenolic amine by cashew oil.

\section{The Other Components}

The pigments and fillers used in coatings curing in water should be anti-corrosion and rust proof, and also have certain hydrophilic reactivity and rust transformed function, such as chromate, phosphate, iron oxide red, iron oxide black etc.. The water-absorbent or water-reactivity agent may be added into coatings curing in water [14]. Coupling agents were selected to improve the adhesion of epoxy resin coatings on the wet surface by Cheng-lou LIU et al [7] and Jian-jun FANG [2]. Some additives were selected to prepare coating curing in sea water by Hongyao Sun such as water absorbent, chlorine absorbent and active diluent etc.[15].

\section{The Application of Surface Tolerant Coatings in China}

The earlier rust-bearing coatings could not adapt to the other surface such as wet or original coatings. Some application cases of surface tolerant coatings in China are listed in Table 4 [8].

Table 4. Some application cases of surface tolerant coatings in China

\begin{tabular}{|c|c|c|c|}
\hline Project name & Original coating system & Repair method & $\begin{array}{l}\text { Repair time } \\
\text { and area }\end{array}$ \\
\hline $\begin{array}{l}\text { The Boiler Steel } \\
\text { Structure of } \\
\text { Shanghai } \\
\text { Waigaoqiao } \\
\text { Power Plant }\end{array}$ & $\begin{array}{l}\text { Inorganic zinc-rich primer+ } \\
\text { micaceous iron oxide epoxy } \\
\text { resin intermediate coating }+ \\
\text { thick film polyurethane } \\
\text { finishing coating }\end{array}$ & $\begin{array}{l}\text { Interseal 670HS epoxy } \\
\text { resin surface tolerant } \\
\text { coating + Interthane } \\
990 \text { polyurethane } \\
\text { finishing coating }\end{array}$ & $\begin{array}{l}\text { In 2011, } \\
\text { about } \\
50,000 \mathrm{~m}^{2}\end{array}$ \\
\hline $\begin{array}{l}\text { Steel Box Girder } \\
\text { of Shanghai } \\
\text { Nanpu Bridge }\end{array}$ & $\begin{array}{l}\text { Zinc rich epoxy primer+ } \\
\text { micaceous iron oxide epoxy } \\
\text { resin intermediate coating } \\
\text { chlorinated rubber finishing } \\
\text { coating }\end{array}$ & $\begin{array}{l}\text { Rust-Oleum } 9100 \\
\text { epoxy resin surface } \\
\text { tolerant coating }\end{array}$ & $\begin{array}{l}\text { In } 2009 \text {, } \\
\text { about } \\
50,000 \mathrm{~m}^{2}\end{array}$ \\
\hline $\begin{array}{l}\text { Steel Box Girder } \\
\text { of Shanghai } \\
\text { Yan'an Road } \\
\text { Viaduct }\end{array}$ & $\begin{array}{l}\text { Zinc rich epoxy primer+ } \\
\text { micaceous iron oxide epoxy } \\
\text { resin intermediate coating }{ }^{+} \\
\text {polyurethane finishing coating }\end{array}$ & $\begin{array}{l}\text { Jota mastic } 87-5 \text { epoxy } \\
\text { resin surface tolerant } \\
\text { coating+Jota Hardtop } \\
\text { aliphatic polyurethane } \\
\text { finishing coating }\end{array}$ & $\begin{array}{l}\text { In } 2009 \text {, } \\
\text { about } \\
100,000 \mathrm{~m}^{2}\end{array}$ \\
\hline
\end{tabular}


By now the number of projects which need maintained or repaired increases with the enlarging scale of the engineering construction in China. Especially these projects whose substrate surface is difficult to be treated to high cleanliness grade such as Sa $2 \frac{1}{2}$ need the surface tolerant coatings for protecting the steel. The repair method used in Shanghai Nanpu Bridge was also used on steel box girder of Shanghai Yangpu bridge and Shanghai Xupu bridge and the surface cleanliness level in Table 4 is ISO8501 St2.

\section{The Performance Evaluation of Surface Tolerant Coatings}

\section{The Specification}

The first specification about surface tolerant coatings (HG/T 4564-2013) "Surface tolerant epoxy coatings" was published in China. The performance requirements of surface tolerant epoxy coating are listed in Table 5.

When these tests including adhesive force, water resistance and salt fog resistance test in Table 5 are carried out, the steel surface is required to be corroded in salt spray test chamber. But the requirements of the steel surface treatment of other test items in Table 5 are in accord with the requirements of the relevant specifications. The steel surface state before construction was not classified in the specification, so it is difficult to use this specification to design the surface tolerant coating system.

Table 5 The performance requirements of surface tolerant epoxy coating (HG/T 4564-2013)

\begin{tabular}{|l|l|l|}
\hline Item & Indicator & Test method \\
\hline State in vessel & Normal & Stir the coating \\
\hline Density $\left[\mathrm{g} / \mathrm{cm}^{3}\right]$ & $\begin{array}{l}\text { In conformity with the agreed value and } \\
\text { the allowable deviation } \pm 0.05\end{array}$ & GB/T6750-2007 \\
\hline Nonvolatile content [\%] & $\geqslant 80$ & GB/T1725-2007 \\
\hline Drying time[h] & $\begin{array}{l}\text { The surface drying time } \leqslant 4 ; \\
\text { The hard drying time } \leqslant 24\end{array}$ & GB/T1728-1979 \\
\hline Bending test [mm] & $\leqslant 2$ & GB/T6742-2007 \\
\hline Impact resistance [cm] & 50 & GB/T1732-1993 \\
\hline Adhesive force[MPa] & $\geqslant 3$ (pull-off method) & GB/T5210-2006 \\
\hline Water resistance (240h) & Normal & GB/T1733-1993 \\
\hline Salt fog resistance (1000h) & $\begin{array}{l}\text { No bubble, no rust, no cracking, no peeling } \\
\text { and other defects of coating film }\end{array}$ & GB/T1771-2007 \\
\hline $\begin{array}{l}\text { Compatibility with original } \\
\text { coating (if necessary) }\end{array}$ & Normal & Field test \\
\hline
\end{tabular}

\section{The Performance Evaluation of Surface Tolerant Coatings}

Ya-liang YANG et al [16] introduced the performance evaluation status of surface tolerant coatings in his paper. The surface states including rust surface, wet surface, chloride-bearing surface and original coatings surface were obtained by spraying water or salt water or using other coating to express the original coating on the steel surface. Then the surface tolerant coating was coated on these special surfaces. At last the performance of surface tolerant coating was tested. But that there is not regular uniform evaluation standards about the quantity of water, the content of chlorine ion, the corrosion degree on the steel surface and the adhesive strength of coating in this paper shall cause inconformity of the test results.

The performance evaluation of surface tolerant coatings includes the evaluation of physical properties, corrosion resistance and construction performance. The evaluation of physical properties mainly includes adhesive strength, flexibility, impact strength, hardness, appearance of the coating and so on. The evaluation of adhesive strength is the most important. The anticorrosion performance evaluation mainly includes the resistance to salt, resistance to water, resistance to solvent oil, resistance to salt fog, resistance to hot humid air and so on. The construction performance evaluation mainly includes the requirement of surface treatment, environmental 
requirements, the coating viscosity, leveling property of coating, sagging property of coating, drying time, coating thickness, construction property of coating curing in water, and match for the original coating and the subsequent coating etc.. The evaluation indicators of surface tolerant coatings need to be confirmed by a large number of experiments and the results of the test must be good reproducibility.

\section{Summary}

Many built engineering such as hydraulic engineering shall gradually come to the repair and maintenance phase in China. In most cases the quality of repaired projects cannot meet the high quality requirements of new project. So the demand of surface tolerant coatings is increasing and it has a broad market. According to the above, these works below about surface tolerant coatings need intensive study in the future: the development of surface tolerant coatings with the ability of tolerant to several surface states; the development of high performance water-base surface tolerant coatings; the establish of the evaluating method and criteria of surface tolerant coatings; the set of specification about different surface tolerant coatings and so on.

\section{Acknowledgements}

This work is financially supported by the National Natural Science Foundation of the P. R. China (51279110).

\section{References}

[1] Hong-yao SUN,Ju-fu SUN, Yu-jun DAI et al.. Information of Surface Engineering, 5(2013): 17-22. In Chinese.

[2] Jian-jun FANG, Ke XU, Sheng-jun MA et al. Chinese Patent 201210470708.4.(2012).

[3] Jin-ren WANG, Yu-bo WU, Hong-wei LIU et al. Chinese Patent 201010101626.3. (2010).

[4] Zhi-qiang PENG. Development and Application of Materials, 2(2004):27-30. In Chinese.

[5] Xiao-hong YANG, Xiao-iun GUO, Shao-ming DUAN et al. Paint \& Coating Industry, 10(1998): 1-5. In Chinese.

[6] Ya-jun GUO, Jie LIU, Zhun CAI et al. Chinese Patent 200810032809.7. (2008).

[7] Cheng-lou LIU, Guo-jun TANG. Chinese Patent201210206977.X.(2012).

[8] Min-feng LI. Shanghai Coatings, 3(2011):33-35. In Chinese.

[9] Zhen-bo YANG,Yun-de LI, Hua SHI. Electroplating \& Finishing, 1(2009):61-63. In Chinese.

[10] Guang-jun LI, Tao-sen HUANG. Materials Protection, 8(1990): 4-6. In Chinese.

[11] Yun-lu CAI, Da-qing FANG, Zheng WU. Chinese Patent 200810008750.8. (2008).

[12] Xiang-ou WU. Chinese Patent 02107263.9. (2002).

[13] Ji-su CHEN,Zhi-wang ZHU,Guo-peng WANG et al. Chinese Patent 200910017154.0. (2009).

[14] Ying-tao JIANG. The Coating Process (Fifth volume). Beijing: Chemical Industry Press, 1992.

[15] Hong-yao SUN, Gao-xia SUN, Sen-lin LI et al. Chinese Patent 201410502197.(2014).

[16] Ya-liang YANG, Sheng-jun MA. Shanghai Coatings, 4(2012):30-33. In Chinese. 